\title{
Öğretmenlerin Örgütsel Erdemlilik Düzeyleri ile İş Doyumları Arasındaki İlişkinin İncelenmesi
}

\section{An Examination of the Relationship between the Levels of Organizational Virtuousness and Job Satisfaction of Teachers}

\author{
Gökhan KAHVECI*
}

\author{
Selda KOTBAŞ ${ }^{* *}$
}

\author{
Saadet BAYRAM ${ }^{* * *}$
}

Received: 29 May 2018

Research Article

Accepted: 18 October 2018

\begin{abstract}
This research is done by aiming to determine the relationship between the levels of organizational virtues and job satisfaction of teachers. This research in which 298 teachers, who are working in primary and secondary schools of Trabzon province, participated is done by using relational scanning model. "Organizational Virtuousness Scale" and "Job Satisfaction Scale" scale were used to collect data in the study. The t-test, one-way ANOVA, correlation and multiple linear regression analysis were used in the analysis of the data obtained from the research. According to the results of the research, teachers' perception of organizational virtuousness and job satisfaction is high. While the perceptions of organizational virtuousness differed significantly according to gender variables; age, years of service and school level. However, the level of job satisfaction of teachers did not show any significant difference in terms of gender, age, service years and school level variables. There is a moderately significant positive relationship between teachers' organizational virtuousness perceptions and job satisfaction levels. Moreover, organizational virtuousness has been found to be a significant predictor of job satisfaction. Various suggestions were presented based on the results of the research.
\end{abstract}

Keywords: teacher, virtuousness, organizational virtuousness, job satisfaction.

ÖZ: Bu araştırma öğretmenlerin örgütsel erdemlilik ile iş doyumları arasındaki ilişkinin belirlenmesi amacıyla yapılmıştır. Trabzon il merkezinde ilk ve ortaokullarda görev yapmakta olan 298 öğretmenin katıldı̆̆ı araştırma ilişkisel tarama modelindedir. Araştırmada verilerin toplanması amacıyla "Örgütsel Erdemlilik Ölçeği ve "İş Doyumu Ölçeği” ölçeği kullanılmıştır. Araştırmadan elde edilen verilerin analizinde t-Testi, Tek Yönlü Varyans Analizi (ANOVA), korelasyon ve çoklu doğrusal regresyon analizi kullanılmıştır. Araştırma sonuçlarına göre öğretmenlerin örgütsel erdemlilik ve iş doyumu algıları yüksek düzeydedir. Öğretmenlerin örgütsel erdemlilik algıları cinsiyet değişkenine göre anlamlı farklılık gösterirken; yaş, hizmet yılı ve okul kademesi değişkenlerine göre anlamlı farklılık göstermemektedir. Bunun yanında öğretmenlerin iş doyumu düzeyleri cinsiyet, yaş, hizmet yılı ve okul kademesi değişkenleri açısından anlamlı farklılık göstermemektedir. Öğretmenlerin örgütsel erdemlilik algıları ile iş doyumu düzeyleri arasında pozitif yönde orta düzeyde anlamlı bir ilişki bulunmaktadır. Ayrıca örgütsel erdemliliğin iş doyumunun anlamlı bir yordayıcısı olduğu görülmüştür. Araştırma sonuçlarına dayalı olarak çeşitli öneriler sunulmuştur.

Anahtar kelimeler: öğretmen, erdemlilik, örgütsel erdemlilik, iş doyumu.

\footnotetext{
*Corresponding Author: Asst. Prof. Dr., Recep Tayyip Erdogan University, Rize, Turkey, gokhan.kahveci@erdogan.edu.tr

Postgraduate Student, Recep Tayyip Erdogan University, Rize, Turkey, kotbasselda@ gmail.com

**** Postgraduate Student, Recep Tayyip Erdogan University, Rize, Turkey, saadetbayram.13@ gmail.com
}

\section{Citation Information}

Kahveci, G., Kotbaş, S., \& Bayram, S. (201?). Öğretmenlerin örgütsel erdemlilik düzeyleri ile iş doyumları arasındaki ilişkinin incelenmesi. Kuramsal Eğitimbilim Dergisi [Journal of Theoretical Educational Science], 12(1), 205-226. 


\section{Giriş}

Örgütlerin verimli çalışma ve başarılı olabilme gayelerine yönelik olarak yapılan araştırmalar son zamanlarda artış göstermiştir. Örgütler, mekanik birer sistemden ibaret değildir, aksine örgütler fizyolojik yapılarından ziyade sosyal boyutlarıyla var olurlar ve varlıklarını sürdürürler (Cameron, 2011). Söz konusu sosyal boyutun örgüt bileşenlerine yansımasıyla örgüt kültürü oluşur (Aktan, 1999). Örgüt kültürü, dürüstlük, paylaşım yanlısı olma, alçakgönüllülük, iletişimin iyiliği gibi unsurları içerir ve bu unsurların bir araya gelmiş hali örgütün erdem boyutunu ifade eder. Bireyin ahlaki iyiliği olarak tanımlanan erdem olgusu çerçevesinde davranışlar sergilemeyi gerektiren erdemlilik kavramının temelinde insan onuruna yakışacak şekilde iyiliğe yönelme eğilimi vardır (Comte-Sponville, 2004). Erdemli kişi, doğruyu arar, bilinçli olarak yanlış yapmaz, haksızlığa göz yummaz, anlayış, yardımseverlik, paylaşımcılık gibi insani değerlere sahiptir ve bu değerlerin gerektirdiği biçimde hayatını sürdürür (Ocak, 2011). Erdemlilik, insan unsurunun yer aldığı bütün sistemler için önem arz eder (Gül \& Gökçe, 2008). Bu sistemlerden biri olan örgüt, bireylerin ortak amaçlar doğrultusunda bir araya gelmesiyle oluşur ve örgütsel oluşumların hedeflerine ulaşabilmesi noktasında sistem bünyesinde sergilenen erdemli davranışların rolü büyüktür (Akbolat, Durmuş, \& Özgün, 2017). Söz konusu davranışlar; eşgüdüm, sorumluluk, hiyerarşi gibi örgüt bileşenlerinin örgüt yararına kullanılmasını sağlar (Aktan, 1999).

\section{Erdemlilik ve Örgütsel Erdemlilik}

Erdemlilik, insanlık durumunun en iyisi ve insanın en yüksek özlemleri olarak ifade edilmekte ve insanoğlunun ideal mükemmellik durumu olarak tanımlamaktadır (Arjoon, 2000; Bright, Cameron, \& Caza, 2006). Örgütsel erdemlilik ise, örgütlerin sistemsel iyiliğini, ahlaki seviyesini, sosyal ve fizyolojik yönden gelişmişliğini, hoşgörü, dürüstlük, sayg1, sabır gibi örgüt içi değerlere sahip olma düzeyini ifade eder (Cameron, 2011). Örgütsel erdemlilik, örgüt içinde var olan bireylerin eylemlerinde ve algılarında gösterdiği erdemli davranışların örgüte yansımasıdır (Vallet, 2010). Başka bir deyişle örgütsel erdemlilik, örgüt üyelerinin yükselen davranışlarını ifade etmektedir (Riberio \& Rego, 2009). Örgütsel erdeme sahip olmak, erdemliliği yansitan değerler açısından var olan duruma uyum sağlamak değil örgütsel değerlerin gelişmesi için çaba göstermek ve örgütü daha üst düzeye ulaştırmaya çalışmaktır (Kaynak, 2007). Peterson (2003) araştırmasında örgütsel erdemliliğin toplumsal iyilik, ahlaka bağlı olma ve insani etki olarak üç temel unsurdan oluştuğunu ve üç bileşenin birbirini tamamlar nitelikte olduğunu ifade etmiştir. Erdemliliğin örgütlerdeki varlık alanı bireylerdir ve erdemli bir örgüt için bireylerin hoşgörü, etkin iletişim, sosyal yönden gelişmişlik, yardıma açık olma, özveri gibi değerlere sahip olması gerekir (Collins, 2001). Örgütsel erdemlilik; dürüstlük, güven, merhamet, iyimserlik, bağışlayıcılık boyutlarından oluşmaktadır. Bu boyutlardan güven bireyler arasındaki anlayış ve hoşgörünün oluşturduğu bağ olarak tanımlanırken dürüstlük boyutunda adil olma ve doğruyu savunma, merhamet boyutunda yardımlaşma, iyimserlik boyutunda sorunlara karşı başarıya inanma vurgulanır, bağışlayıcılık ise olası hataların affedilebilmesi ve telafi imkanı verilmesi olarak ifade edilir (Rego, Riberio, \& Cunha, 2010).

Örgütsel erdemlilik örgütün fizyolojik ve sosyal yapısı açısından önemlidir; ortak amaç, sorumluluk, hiyerarşi, gelişme, yenilik, sistem, stratejik güç gibi unsurların örgüt 
faydasına kullanılabilmesi için örgüt bileşenlerinin kilit noktası olan bireylerin erdemli davranışlar sergilemesi gerekir (Fernando \& Almeida, 2012). Özkalp ve Kocacık (1994) bireyin kişiliği ve erdemlilik düzeyi ile parçası olduğu örgütün yapısı arasındaki uyum arttıkça örgütsel erdemlilik düzeyinin de artacağını belirtir. Yüksek erdemlilik seviyesine ulaşmış örgütlerde hedeflenen başarı ile mevcut başarı arasındaki fark azdır ve bu örgütler daha az sorunla karşılaşırlar, yaşanan olumsuzlukları giderme ve örgüt lehine çevirme noktasında daha başarılıdırlar (Torlak, 2008). Yukarıdaki bilgiler 1şı̆̆ında örgütlerde bireylerin erdemli davranışlar sergilemesinin uyumu arttırdığı, sorunları azalttığı ve örgütsel başarıyı beraberinde getirdiği görülmektedir. Bu bağlamda sorunların daha az yaşanıldığı ve uyumun daha fazla olduğu örgütlerde çalışanların işlerinden daha fazla doyum alması beklenmektedir.

\section{İş Doyumu}

İş doyumu bir çalışanın işinden memnuniyet derecesidir (Schultz \& Schultz, 1986). Locke iş doyumunu; "bir kişinin yaptığı işe karşı hoş ya da olumlu duygular beslemesi" olarak tanımlamaktadır (Luthans, 1994). Çalışanların kendi amaçlarının örgütün amaçları ile tutarlı olması, çalışanların örgütten bekledikleri ödüller ile elde ettikleri ödüllerin paralellik göstermesi iş doyumu ile yakından ilişkilidir (İşcan \& Timuroğlu, 2007). Çalışanların iş doyumuna ulaştığı örgütlerde, örgütün verimliliği ve refahı artar (Roodt, Rieger, \& Sempane, 2002). Saari ve Judge'ye (2004) göre çoğu işveren, örgütün optimal işleyişinin kısmen çalışanların iş doyumu düzeyine bağlı olduğunu dolayısıyla işverenler için "mutlu çalışanlar üretken çalışanlar" ifadesinin önemli olduğunu belirtmektedir. Luthans’a (1994) göre çalışanlar meslektaşlarına göre daha çok çalışıp daha az ödüllendirilirse işlerine ve çalışma arkadaşlarına karşı olumsuz duygular beslerler. Yapılan araştırmalar iş tatminini etkileyen birçok faktörün bulunduğunu göstermiştir. Çalışanın kişiliği iş doyumunu etkileyen faktörlerden biridir. Araştırmalarda çalışanın kişilik özelliği ile iş doyumu arasında korelasyonel olarak anlamlı ilişkiler bulunmuştur (Saari \& Judge, 2004). Çalışmalar aynı zamanda vicdanlılık, dişadönüklük gibi kişilik özelliklerinin iş doyumunu etkileyebileceğini göstermiştir (Judge, Heller, \& Mount, 2002). Örgütler çalışanların kişiliğini etkileyemeyeceğinden çalışan-iş uyumunu yakalama yoluna gitmektedir. $\mathrm{Bu}$ sayede çalışanların iş doyumunu arttırmak amaçlanmaktadır (Saari \& Judge, 2004).

İş doyumu incelenirken iş yaşamında bireylerin iç dünyalarının, ruh hallerinin, duygu durumlarının giderek önem kazanması ve diğer değişkenleri etkilemesi ile birlikte motivasyon kuramları da önem kazanmıştır. Maslow’un İhtiyaçlar Hiyerarşisi, Herzberg'in Çift Faktör ve Adams'ın Eşitlik Kuramları iş doyumu araştırılırken kullanılan kuramlardandır (Yelboğa, 2007). Maslow'un İhtiyaçlar Hiyerarşisi kuramına göre çalışanların hiyerarşik özelliklere sahip ihtiyaçları çalıştığı kurumda karşılanabiliyorsa, çalışanlar kuruma karşı olumlu duygular besler ve bu sayede çalışanların iş doyumu artar (Schermerhorn, Hunt, Osborn, \& Uhl-Blen, 2010). Herzberg'in Çift Faktör Kuramına göre; yüksek ücret veya kademe ilerlemesi çalışanların iş doyumunu arttırmamakta ancak eksiklikleri motivasyon düşüşüne sebep olmaktadır. Herzberg'e göre iş doyumunu yükselten en önemli etmen çalışanı onurlandırmaktır. Psikolojik ve sosyal destek iş doyumuna daha fazla etki etmektedir. Adams'ın Eşitlik Teorisine göre ise çalışanlar kendilerini iş arkadaşları ile kıyaslamaktadırlar. Çalışanların bireysel potansiyelleri ve emeklerinin karşılığında 
uygun maaş, terfi vb. güdüleyicileri almaları motivasyonu ve iş doyumunu arttırır (Schermerhorn ve diğ., 2010).

İş doyumunun alt boyutları içsel ve dişsal olmak üzere iki başlık altında incelenmiştir. Herzberg' in Çift Faktör Kuramına göre başarı, sorumluluk, ilerleme, büyüme gibi faktörler içsel boyutta; kurum politikaları, denetimin kalitesi, çalışma şartları, maaş, güvenlik gibi faktörler dışsal boyuta bulunmaktadır (Schermerhorn ve diğ., 2010). Öğretmenler için iş doyumu öğretmenin mesleki rolüne karşı beslediği duyguları ve öğretimden beklentisini ifade eder (Zembylas \& Papanastasiou, 2005). Öğretmenlerin okuldaki performansları iş doyumu ile büyük oranda ilişsilidir. Öğretmenlerin çalıştıkları kuruma veya mesleklerine karşı pozitif bir tutum sergilemeleri iş doyumunun yüksek olduğunun, çalıştıkları kuruma veya mesleklerine karşı negatif bir tutum segilemeleri iş doyumunun düşük olduğunu göstermektedir. Öğretmenlerin çalıştıkları kurumda mevcut potansiyellerini ortaya çıkaramamalarının veya kurumdan ayrılma isteğinde olmalarının düşük iş doyumu ile bağlantılı olması mümkündür (Özdemir \& Yirmibeş, 2016).

\section{Örgütsel Erdemlilik ile İş Doyumu Arasındaki İlişki}

Bireylerin hem örgütsel hem de bireysel olarak erdemli davranışlar sergilemesi örgütün başarısını arttırmakta ve örgütlerde olumlu bir iklimin meydana getirmektedir. (Nartgün \& Dilekçi 2016). Bunun yanında erdemli davranışlar gösteren çalışanların zorunlu olmadıkları halde örgütün kalitesine ilişkin çalışmalara katılarak bilgilendiği ve bu bilgilerini kullanarak daha iyi performans sergilediği bununla birlikte örgütün gelişimi için yapıcı önerilerde bulunduğu belirtilmektedir (Budiman, Anantadjaya, \& Prasetyawati, 2014). Sezgin ve Kılınç (2012) yaptıkları araştırmada mesleki tükenmişlik ile erdemlilik arasında negatif yönde anlamlı bir ilişkinin olduğunu bulmuşlardır. Öğretmenlerin erdemlilik algılarının azalmasının tükenmişliklerini arttırdığı görülmektedir. $\mathrm{Bu}$ durumun öğretmenlerin iş doyumu algılarını da olumsuz yönde etkileyeceği söylenebilir. Akbolat, Durmuş ve Özgün'ün (2017) yaptıkları araştırmada ise örgütsel erdemliliğin personel güçlendirme üzerinde anlamlı bir etkisinin olduğu görülmüştür. $\mathrm{Bu}$ sonuca göre örgütsel erdemlilik algısının yüksek olduğu örgütlerde çalışanların fikirlerini rahatça ifade edebildiği, kendilerine güvendiği ve örgüt içerisinde alınan kararlara katıldığı söylenebilir. Kendini rahat ifade edebilen ve örgütün başarısında kendisinin de katkısının olduğunu düşünen çalışanların iş doyumlarının da artacağı düşünülmektedir. Nitekim Mehboob ve Bhutto (2012) yaptıkları çalışmada erdemlilik ile iş doyumu arasında orta düzeyde pozitif yönde ilişki olduğu sonucuna ulaşmışlardır. Bununla birlikte yapılan farklı çalışmalarda örgütsel erdemliliğin örgütsel bağlılığı ve örgütsel vatandaşlık davranışını olumlu yönde etkilediği görülmüştür (Kooshki \& Zeinabadi, 2015; Kooshki \& Zeinabadi, 2016). Öğretmenlerin okula olan bağlılıklarının artmasının iş doyumlarını da arttırdığı yapılan çalışmalarda görülmektedir (Aydın, Akyüz, Yıldırım, \& Köse, 2017; Demirtaş, 2010; Demirtaş; 2015; Getahun, Tefera, \& Burichew, 2016; Karataş \& Güleş, 2010; Werang \& Agung, 2017; Wu \& Short, 1996). Bununla birlikte okullarda yöneticilerin sergiledikleri liderlik davranışları da örgütsel erdemliliği etkilemektedir. Şeffaf ve güvenilir bir çalışma ortamı sağlayan liderler örgüt içerisinde erdemlilik algısını da arttırmaktadır (Demirdağ, 2015). Okullarda öğretmenlerin sergiledikleri erdemli davranışların okul yöneticileri 
tarafından desteklenmesinin öğretmenlerin iş doyumlarının artmasında ve okulun başarısında önemli olduğu düşünülmektedir.

Yukarıdaki bilgiler göz önüne alındığında erdemlilik kavramının örgütlerin başarısı ve devamlılığı için önemli bir faktör olduğu görülmektedir. Bu durum eğitim örgütleri için düşünüldüğünde önemi daha da artmaktadır. Çünkü geleceğin nesillerini yetiştiren öğretmenlerin erdemli davranışlar sergilemesi ve öğrencilerine bu anlamda örnek teşkil etmesi önemlidir. Örgütsel erdemlilik düzeyi yüksek olan okulların daha başarılı olması beklenmektedir. Okulların başarı düzeyinin yükselmesinin öğretmenlerin iş doyumlarını da etkilyeceği öngörülmektedir. Bu bağlamda örgütlerin erdemlilik düzeyleri ile öğretmenlerin iş doyumları arasındaki ilişkinin belirlenmesinin ilgili literature katkı sağlayacağı düşünülmektedir. Bu bağlamda araştırmanın temel amacı; öğretmenlerin algılarına göre örgütsel erdemlilik ve iş doyumu arasındaki ilişkiyi belirlemektir. $\mathrm{Bu}$ temel amaç çerçevesinde aşağıdaki sorulara cevap aranmıştır.

1. Öğretmenlerin görüşlerine göre örgütsel erdemlilik ve iş doyumu algıları nasildir?

2. Öğretmenlerin örgütsel erdemlilik algıları ve iş doyumuna yönelik görüşleri cinsiyet, yaş, hizmet yılı ve okul kademesi değişkenleri bakımından anlamlı olarak farklılaşmakta mıdır?

3. Öğretmenlerin örgütsel erdemlilik ve iş doyumu algıları arasında anlamlı bir ilişki var mıdır?

4. Öğretmenlerin örgütsel erdemlilik düzeyleri, iş doyum düzeylerini anlamlı olarak yordamakta midir?

\section{Yöntem}

\section{Araştırmanın Deseni}

İlkokul ve ortaokullarda görev yapmakta olan öğretmenlerin örgütsel erdemlilik düzeyleri ile iş doyumu düzeyleri arasındaki ilişkinin belirlenmesini amaçlayan bu çalışmada korelasyon türü ilişkisel tarama modeli kullanılmıştır. Korelasyon türü ilişkisel tarama modellerinde iki veya daha fazla değişken arasında birlikte değişimin var olup olmadığı (Balnaves \& Caputi, 2001; Erkuş, 2011) ve eğer değişim varsa bu değişimin düzeyinin belirlenmesi amaçlanır (Karasar, 2005).

\section{Evren ve Örneklem}

Araştırmanın evrenini Trabzon il merkezinde ilkokul ve ortaokullarda görev yapmakta olan öğretmenler oluşturmaktadır. Örneklem ise evrenden basit seçkisiz örnekleme yöntemi ile seçilen 298 öğretmendir. Örnekleme ilişkin demografik bilgilere bakıldığında cinsiyet dağılımına göre öğretmenlerin 176's1 (\%59.1) kadın ve 122'si (\%40.9) erkektir. Yaş dağılımına göre katılımcılardan 103'ü (\%34.6) 20-30 yaş aralığında, 136'sı (\%45) 31-40 yaş aralığında, 38'i (\%12.8) 41-50 yaş aralığında ve 21'i (\%7) 51 ve üzeri yaş aralığında bulunmaktadır. Katılımcılardan 69'u (\%23.2) sınıf öğretmeni, 229'u (\%76.8) ise branş öğretmenidir. Katılımcılar hizmet yıllarına göre incelendiğinde 1-10 yıl arasında görev yapan öğretmen sayısının 166 (\%55.7), 11-20 yıl arasında görev yapan öğretmen sayısının 92 (\%30.9), 21 ve üzeri yıl görev yapan öğretmen sayısının ise 40 (13.4) olduğu görülmüştür. Katılımcıların 83’ü (\%27.9) ilkokulda, 215'i (\%72.1) ortaokulda görev yapmaktadır. 


\section{Verilerin Toplanması}

$\mathrm{Bu}$ araştırmada verilerin toplanması amacıyla Trabzon İl Milli Eğitim Müdürlüğüne bağlı ilkokul ve ortaokul kurumlarında görev yapmakta olan öğretmenlere ulaşılmıştır. Araştırmaya katılım gönüllülük esasına dayalı olduğundan istekli öğretmenlerle çalışılmıştır. Veri toplama formu araştırmacılar tarafından tarafından bizzat uygulanmıştır. Araştırmada toplam 330 ölçek uygulanmış ve toplanan ölçek formları incelenmiştir. İnceleme sonucunda 32 ölçek formu araştırma dışında tutulmuştur. Bu işlem sonucunda toplam 298 ölçek formu analize uygun bulunmuştur.

\section{Veri Toplama Araçları}

Araştırmada verilerin toplanması amacıyla kullanılan ölçek formu üç bölümden oluşmaktadır. Birinci bölümde katılımcıların "cinsiyet, yaş, hizmet yılı, okul kademesi" gibi demografik bilgilerini belirlemeye yönelik "Kişisel ve Mesleki Bilgi Formu", ikinci bölümde "Örgütsel Erdemlilik Ölçeği" üçüncü bölümde ise "İş Doyumu Ölçeği" kullanılmıştır. Aşağıda araştırmada kullanılan ölçeklere ilişskin bilgiler yer almaktadır.

Örgütsel Erdemlilik Ölçeği. Öğretmenlerin erdemlilik algılarını belirlemek amacıyla kullanılan "Örgütsel Erdemlilik Ölçeği” Cameron, Bright ve Caza (2004) tarafından geliştirilmiş olup ölçeğin Türkçeye uyarlanması, geçerlik ve güvenirlik çalışmaları ise Erkmen ve Esen (2004) tarafından yapılmıştır. Ölçek, dürüstlük ve bağışlayıcılık boyutunda 9 , güven ve nezaket boyutunda 3 , iyimserlik boyutunda 3 madde olmak üzere toplam 15 maddeden oluşmaktadır. Ölçeğin maddeleri, tamamen katılıyorumdan (6) hiç katılmıyoruma (1) dek sıralanan altılı derecelendirme ile değerlendirilmiştir. Ölçekteki tüm maddeler olumlu olduğu için ters puanlamaya gerek duyulmamıştır. Ölçekten alına yüksek puanlar erdemlilik algısının yüksek düşük puanlarsa erdemlilik algısının düşük olduğunu gösterir. Ölçeğin bu çalışma için geçerliğine ilişkin iki eğitim yönetimi bir ölçme ve değerlendirme alanında uzman olan üç akademisyenin görüşü alınmıştır. Ölçeğin geliştirilmesi esnasında yapılan güvenirlik çalışmasında ulaşılan Cronbach's Alpha katsayısı .94 olarak verilmiştir. Bu çalışmada ise ölçeğin dürüstlük ve bağışlayıcılık boyutu için .94; güven ve nezaket boyutu için .86 ve iyimserlik boyutu için .89 olarak bulunmuştur. Ölçeğin toplamı için hesaplanan güvenirlik katsayısı ise .96 şeklindedir.

İş Doyumu Ölçeği. Bu araştırmada öğretmenlerin iş doyumlarını ölçmek amacıyla Minnesota İş Doyum Ölçeğinin (Minnesota Satisfaction Questionnaire) kısa formundan yararlanılmıştır. Minnesota İş Doyumu ölçeği içsel (12 madde) ve dışsal (8 madde) olmak üzere iki alt boyut ve toplam 20 maddeden oluşmaktadır. Ölçeğin bu çalışma için geçerliğine ilişkin iki eğitim yönetimi bir ölçme ve değerlendirme alanında uzman olan üç akademisyenin görüşü alınmıştır. Ölçeği Türkçe'ye uyarlayan ve ölçeğe güvenilirlik çalışması yapan Baycan (1985) güvenilirlik katsayısını .77 olarak bulmuştur. Karababa ve Acun-Kapıkıran (2014) ölçeğin güvenilirliğini 90 ve Özkan (2017) .88 olarak bulmuşlardır. Bu çalışmada ise ölçeğin içsel doyum boyutu için 90 dışsal doyum boyutu için .85 güvenilirlik katsayısı hesaplanmıştır. Ölçeğin toplamı için ise hesaplanan güvenirlik katsayısı .92 şeklindedir.

\section{Verilerin Analizi}

Verilerin analizi için SPSS paket programından faydalanılarak bir takım istatistiksel analizler yapılmıştır. Öğretmenlerin kişisel ve mesleki bilgi formlarına bağlı 
olarak ortalama, frekans standart sapma ve yüzde değerlerinden faydalanılarak betimsel istatistikler yapılmıştır. Öğretmenlerin örgütsel erdemlilik algıları ve iş doyumlarının yorumlanmasında ortalama ve standart sapma değerlerinden faydalanılmıştır. Öğretmenlerin örgütsel erdemlilik ve iş doyumlarına ilişkin algılarının cinsiyet, yaş, hizmet yılı ve okul kademesi değişkenleri açısından farklılaşıp farklılaşmadığını belirlemek için normallik varsayımına bağlı olarak parametrik testlerden t- Testi, Tek Yönlü Varyans Analizi (ANOVA) kullanılmıştır. Farklılığın hangi gruplar arasında olduğunu belirlemek amacıyla LSD testine bakılmış ve anlamlılık düzeyi .05 olarak alınmıştır. Öğretmenlerin algılarına göre örgütsel erdemlilik ile iş doyumu arasındaki ilişkiyi belirlemek amacıyla korelasyon analizi yapılmıştır. Korelasyon analizi bulguları değerlendirilirken, korelasyon katsayısının 0.70-1.00 arasında olması yüksek; 0.70-0.30 arasında olması orta; 0.30-0.00 arasında olması ise düşük düzeyde bir ilişkinin olduğunu göstermektedir (Büyüköztürk, 2009). Ayrıca öğretmenlerin örgütsel erdemlilik algılarının iş doyumlarını yordamasına yönelik regresyon analizi gerçekleştirilmiştir.

\section{Bulgular}

İlkokul ve ortaokullarda görev yapan öğretmenlerin örgütsel erdemlilik ve iş doyumu algıları Tablo 1'de verilmiştir.

Tablo 1

Öğretmenlerin Örgütsel Erdemlilik ve İş Doyumu Algllarına Iliş̧kin Ortalama ve Standart Sapma Değerleri

\begin{tabular}{lccc}
\hline Değişken & $n$ & $\bar{X}$ & Ss \\
\hline Dürüstlük ve Bağışlayıcılık & 298 & 4.42 & 1.00 \\
Güven ve Nezaket & 298 & 4.58 & 1.03 \\
İyimserlik & 298 & 4.40 & 1.02 \\
Örgütsel Erdemlilik & 298 & 4.47 & 0.94 \\
İşsel Doyum & 298 & 3.67 & 0.63 \\
Dişsal Doyum & 298 & 3.37 & 0.67 \\
İş Doyumu & 298 & 3.52 & 0.61 \\
\hline
\end{tabular}

Tablo 1'e bakıldığında öğretmenlerin örgütsel erdemlilik algılarının boyutlara göre ortalamaları dürüstlük ve bağışlayıcılık için $\bar{X}=4.42$, güven ve nezaket için $\bar{X}$ $=4.58$ ve iyimserlik için $\bar{X}=4.40$ 'dır. Örgütsel erdemliliğin toplamı için ise $\bar{X}=4.47$ şeklindedir. Öğretmenlerin örgütsel erdemlilik algılarının en yüksek güven ve nezaket en düşük iyimserlik boyutunda olduğu belirlenmiştir. Bununla birlikte öğretmenlerin iş doyum algı ortalamaları boyut bazında incelendiğinde içsel doyum için $\bar{X}=3.67$, dişsal doyum için $\bar{X}=3.37^{\prime}$ dir. Öğretmenlerin toplam iş doyumu algıları ise $\bar{X}=3.52$ şeklindedir.

Öğretmenlerin örgütsel erdemlilik ve iş doyumu algılarının cinsiyete göre farklılık gösterip göstermediğini belirlemek amacıyla t-Testi yapılmış ve ulaşılan sonuçlar Tablo 2'de verilmiştir. 
Tablo 2

Öğretmenlerin Örgütsel Erdemlilik ve Işs Doyumu Algılarına İlişkin Cinsiyet Değişkeni Açısından t-Testi Sonuçları

\begin{tabular}{|c|c|c|c|c|c|c|c|c|c|}
\hline & Cinsiyet & $n$ & $\bar{X}$ & SS & $\mathrm{F}$ & $p$ & $t$ & SD & $p$ \\
\hline \multirow{2}{*}{ Dürüstlük ve Bağışlayıcılık } & Kadın & 176 & 4.28 & 1.04 & \multirow{2}{*}{1.543} & \multirow{2}{*}{.215} & \multirow{2}{*}{-2.887} & \multirow{2}{*}{296} & \multirow{2}{*}{$.004 *$} \\
\hline & Erkek & 122 & 4.61 & 0.91 & & & & & \\
\hline \multirow{2}{*}{ Güven ve Nezaket } & Kadın & 176 & 4.52 & 1.07 & \multirow{2}{*}{1.074} & \multirow{2}{*}{.301} & \multirow{2}{*}{-1.387} & \multirow{2}{*}{296} & \multirow{2}{*}{.166} \\
\hline & Erkek & 122 & 4.68 & 0.96 & & & & & \\
\hline \multirow{2}{*}{ İyimserlik } & Kadın & 176 & 4.32 & 1.04 & \multirow{2}{*}{.083} & \multirow{2}{*}{.773} & \multirow{2}{*}{-1.579} & \multirow{2}{*}{296} & \multirow{2}{*}{.115} \\
\hline & Erkek & 122 & 4.51 & 0.99 & & & & & \\
\hline \multirow{2}{*}{ Örgütsel Erdemlilik } & Kadın & 176 & 4.37 & 0.97 & \multirow{2}{*}{1.055} & \multirow{2}{*}{.305} & \multirow{2}{*}{-2.103} & \multirow{2}{*}{296} & \multirow{2}{*}{$.036^{*}$} \\
\hline & Erkek & 122 & 4.60 & 0.88 & & & & & \\
\hline \multirow{2}{*}{ İçsel Doyum } & Kadın & 176 & 3.63 & 0.62 & \multirow{2}{*}{.073} & \multirow{2}{*}{.787} & \multirow{2}{*}{-1.063} & \multirow{2}{*}{296} & \multirow{2}{*}{.288} \\
\hline & Erkek & 122 & 3.71 & 0.63 & & & & & \\
\hline \multirow{2}{*}{ Dişsal Doyum } & Kadın & 176 & 3.31 & 0.64 & \multirow{2}{*}{3.100} & \multirow{2}{*}{.079} & \multirow{2}{*}{-1.867} & \multirow{2}{*}{296} & \multirow{2}{*}{.063} \\
\hline & Erkek & 122 & 3.45 & 0.72 & & & & & \\
\hline \multirow{2}{*}{ İş Doyumu } & Kadın & 176 & 3.47 & 0.58 & 11770 & 107 & 1500 & (20) & 110 \\
\hline & Erkek & 122 & 3.58 & 0.64 & & & & & \\
\hline
\end{tabular}

$* \mathrm{p}<.05$

Tablo 2'ye bakıldığında cinsiyet değişkeni açısından öğretmenlerin algıları dürüstlük ve bağışlayıcılık $\left[t_{(296)}=-2.887 ; p<.05\right]$ ve örgütsel erdemlilik ölçeğinin toplamı $\left[t_{(296)}=-2.103 ; p<.05\right]$ için anlamlı farklılık göstermektedir. Elde edilen bu bulguya göre hem dürüstlük ve bağışlayıcılık boyutunda hem de örgütsel erdemliliğin toplamında erkek öğretmenlerin algıları kadın öğretmenlere göre daha yüksek düzeydedir. Bunun yanında öğretmenlerin algıları güven ve nezaket $\left[t_{(296)}=-1.387\right.$; $p>.05]$, iyimserlik $\left[t_{(296)}=-1.579 ; p>.05\right]$, içsel doyum $\left[t_{(296)}=-1.063 ; p>.05\right]$, dişsal doyum $\left[t_{(296)}=-1.867 ; p>.05\right]$ boyutları ve iş doyum ölçeğinin toplamı $\left[t_{(296)}=-1.593\right.$; $p>.05]$ için istatiksel anlamda farklılık göstermemektedir.

Öğretmenlerin örgütsel erdemlilik ve iş doyumu algılarının yaşa göre farklılık gösterip göstermediğini belirlemek amacıyla Tek Yönlü Varyans Analizi yapılmış ve ulaşılan sonuçlar Tablo 3 'te verilmiştir. 
Tablo 3

Öğretmenlerin Örgütsel Erdemlilik ve İş Doyumu Algılarına İlişkin Yaş Değişkeni Açısından Tek Yönlü Varyans Analizi Sonuçları

\begin{tabular}{|c|c|c|c|c|c|c|c|c|c|c|c|}
\hline & Yaş & $n$ & $\bar{X}$ & Ss & V. K & K.T & SD & K.O & $\mathrm{F}$ & $p$ & LSD \\
\hline \multirow{3}{*}{$\begin{array}{l}\text { Dürüstlük ve } \\
\text { Bağışlayıcılık }\end{array}$} & $20-30$ & 103 & 4.27 & 0.99 & GA & 7.996 & 2 & 3.998 & 4.073 & .018 & $3>1$ \\
\hline & $31-40$ & 136 & 4.40 & 1.04 & Gİ & 289.567 & 295 & .982 & & & $3>2$ \\
\hline & 41üzeri & 59 & 4.73 & 0.87 & Toplam & 297.563 & 297 & & & & \\
\hline \multirow{4}{*}{$\begin{array}{l}\text { Güven ve } \\
\text { Nezaket }\end{array}$} & $20-30$ & 103 & 4.52 & 1.06 & GA & .880 & 2 & .440 & .414 & .661 & \\
\hline & $31-40$ & 136 & 4.59 & 1.06 & Gİ & 313.523 & 295 & 1.063 & & & - \\
\hline & 41üzeri & 59 & 4.67 & 0.90 & Toplam & 314.403 & 297 & & & & \\
\hline & $20-30$ & 103 & 4.30 & 1.04 & GA & 5.569 & 2 & 2.785 & 2.687 & .070 & \\
\hline \multirow{2}{*}{ İyimserlik } & $31-40$ & 136 & 4.35 & 1.04 & Gi் & 305.706 & 295 & 1.036 & & & - \\
\hline & 41üzeri & 59 & 4.67 & 0.93 & Toplam & 311.275 & 297 & & & & \\
\hline \multirow{3}{*}{$\begin{array}{l}\text { Örgütsel } \\
\text { Erdemlilik }\end{array}$} & $20-30$ & 103 & 4.36 & 0.95 & GA & 4.076 & 2 & 2.038 & 2.330 & .099 & \\
\hline & $31-40$ & 136 & 4.44 & 0.96 & Gİ & 257.989 & 295 & .875 & & & - \\
\hline & 41üzeri & 59 & 4.69 & 0.83 & Toplam & 262.065 & 297 & & & & \\
\hline \multirow{3}{*}{ İçsel Doyum } & $20-30$ & 103 & 3.67 & 0.60 & GA & .244 & 2 & .122 & .306 & .736 & \\
\hline & $31-40$ & 136 & 3.64 & 0.65 & Gİ & 117.478 & 295 & .398 & & & - \\
\hline & 41üzeri & 59 & 3.72 & 0.63 & Toplam & 117.722 & 297 & & & & \\
\hline \multirow{3}{*}{$\begin{array}{l}\text { Dişsal } \\
\text { Doyum }\end{array}$} & $20-30$ & 103 & 3.29 & 0.65 & GA & 1.848 & 2 & .924 & 2.044 & .131 & \\
\hline & $31-40$ & 136 & 3.36 & 0.67 & Gí & 133.381 & 295 & .452 & & & - \\
\hline & 41üzeri & 59 & 3.51 & 0.72 & Toplam & 135.229 & 297 & & & & \\
\hline \multirow{3}{*}{ İş Doyumu } & $20-30$ & 103 & 3.48 & 0.56 & GA & .750 & 2 & .375 & 1.023 & .361 & \\
\hline & $31-40$ & 136 & 3.50 & 0.62 & Gİ & 108.108 & 295 & .366 & & & - \\
\hline & 41üzeri & 59 & 3.62 & 0.64 & Toplam & 108.858 & 297 & & & & \\
\hline
\end{tabular}

Not: V.K: Varyansın Kaynă̆ı; K.T: Kareler Toplamı; K.O: Kareler Ortalaması; G.A: Gruplar Arası; G.İ: Gruplar $\dot{I}_{c ̧ i}$

Tablo 3'e bakıldığında yaş değişkeni açısından öğretmenlerin algıları dürüstlük ve bağışlayıcılık $\left[F_{(295)}=4.073 ; p<.05\right]$ boyutunda anlamlı farklılık göstermektedir. $\mathrm{Bu}$ farklılığın hangi gruplar arasında olduğunu belirlemek amaciyla yapılan LSD testi sonuçlarına göre 41 ve üzeri [ $\bar{X}=4.73$ ] yaş grubunda bulunan öğretmenlerin algıları 21-30 [ $\bar{X}=4.27$ ve 31-40 [ $\bar{X}=4.40]$ yaş grubunda bulunan öğretmenlerin algılarından daha yüksektir. Bununla birlikte öğretmenlerin algıları örgütsel erdemlik ölçeğinin toplam1 $\left[F_{(246)}=2.330 ; p>.05\right]$, güven ve nezaket $\left[F_{(295)}=.414 ; p>.05\right]$, iyimserlik $\left[F_{(295)}=2.687 ; p>.05\right]$, içsel doyum $\left[F_{(295)}=.306 ; p>.05\right]$, dişsal doyum $\left[F_{(295)}=2.044\right.$; $p>.05]$ boyutları ve iş doyumu ölçeğinin toplamı $\left[F_{(295)}=1.023 ; p>.05\right]$ için yaşa göre istatiksel anlamda farklılık göstermemektedir.

Öğretmenlerin örgütsel erdemlilik ve iş doyumu algılarının hizmet yılına göre farklılık gösterip göstermediğini belirlemek amacıyla Tek Yönlü Varyans Analizi yapılmış ve ulaşılan sonuçlar Tablo 4'te verilmiştir. 
Tablo 4

Öğretmenlerin Örgütsel Erdemlilik ve $\dot{I}_{S ̧}$ Doyumu Algllarına İlişkin Hizmet Yılı Değişkeni Açısından Tek Yönlü Varyans Analizi Sonuçları

\begin{tabular}{|c|c|c|c|c|c|c|c|c|c|c|c|}
\hline & $\begin{array}{l}\text { Hizmet } \\
\text { Yilı }\end{array}$ & $n$ & $\bar{X}$ & Ss & V. K & K.T & SD & K.O & $\mathrm{F}$ & $p$ & LSD \\
\hline \multirow{3}{*}{$\begin{array}{l}\text { Dürüstlük ve } \\
\text { Bağışlayıcılık }\end{array}$} & $1-10$ & 166 & 4.27 & 1.02 & GA & 9.021 & 2 & 4.510 & 4.611 & .011 & $3>1$ \\
\hline & $11-20$ & 92 & 4.56 & 1.00 & Gİ & 288.542 & 295 & .978 & & & $2>1$ \\
\hline & 21üzeri & 40 & 4.70 & 0.82 & Toplam & 297.563 & 297 & & & & \\
\hline \multirow{3}{*}{$\begin{array}{l}\text { Güven ve } \\
\text { Nezaket }\end{array}$} & $1-10$ & 166 & 4.51 & 1.06 & GA & 2.002 & 2 & 1.001 & .945 & .390 & \\
\hline & $11-20$ & 92 & 4.70 & 1.06 & Gİ & 312.401 & 295 & 1.059 & & & - \\
\hline & 21üzeri & 40 & 4.62 & 0.82 & Toplam & 314.403 & 297 & & & & \\
\hline \multirow{3}{*}{ İyimserlik } & $1-10$ & 166 & 4.29 & 1.02 & GA & 4.531 & 2 & 2.266 & 2.179 & .115 & \\
\hline & $11-20$ & 92 & 4.48 & 1.05 & Gİ & 306.744 & 295 & 1.040 & & & - \\
\hline & 21üzeri & 40 & 4.63 & 0.95 & Toplam & 311.275 & 297 & & & & \\
\hline \multirow{3}{*}{$\begin{array}{l}\text { Örgütsel } \\
\text { Erdemlilik }\end{array}$} & $1-10$ & 166 & 4.36 & 0.95 & GA & 4.474 & 2 & 2.237 & 2.562 & .079 & \\
\hline & $11-20$ & 92 & 4.58 & 0.96 & Gİ & 257.591 & 295 & .873 & & & - \\
\hline & 21üzeri & 40 & 4.65 & 0.79 & Toplam & 262.065 & 297 & & & & \\
\hline \multirow{3}{*}{ İçsel Doyum } & $1-10$ & 166 & 3.72 & 0.61 & GA & 1.779 & 2 & .889 & 2.263 & .106 & \\
\hline & $11-20$ & 92 & 3.55 & 0.67 & Gİ & 115.944 & 295 & .393 & & & - \\
\hline & 21üzeri & 40 & 3.72 & 0.60 & Toplam & 117.722 & 297 & & & & \\
\hline \multirow{3}{*}{ Dişsal Doyum } & $1-10$ & 166 & 3.35 & 0.66 & GA & 1.937 & 2 & .968 & 2.143 & .119 & \\
\hline & $11-20$ & 92 & 3.31 & 0.69 & Gİ & 133.292 & 295 & .452 & & & - \\
\hline & 21üzeri & 40 & 3.57 & 0.68 & Toplam & 135.229 & 297 & & & & \\
\hline \multirow{3}{*}{ İş Doyumu } & $1-10$ & 166 & 3.53 & 0.59 & GA & 1.385 & 2 & .692 & 1.901 & .151 & \\
\hline & $11-20$ & 92 & 3.43 & 0.64 & Gí & 107.473 & 295 & .364 & & & - \\
\hline & 21üzeri & 40 & 3.64 & 0.60 & Toplam & 108.858 & 297 & & & & \\
\hline
\end{tabular}

Not: V.K: Varyansın Kaynağı; K.T: Kareler Toplamı; K.O: Kareler Ortalaması; G.A: Gruplar Arasl; G.I: Gruplar $\dot{I}_{c ̧ i}$

Tablo 4'e bakıldığında, hizmet y1lı değişkeni açısından öğretmenlerin algıları dürüstlük ve bağışlayıcılık $\left[F_{(295)}=4.611 ; p<.05\right]$ boyutunda anlamlı farklılık göstermektedir. $\mathrm{Bu}$ farklılığın hangi gruplar arasında olduğunu belirlemek amaciyla yapılan LSD testi sonuçlarına göre 21-üzeri [ $\bar{X}=4.70]$ ve $11-20$ yıl [ $\bar{X}=4.56]$ hizmet süresine sahip öğretmenlerin algıları 1-10 yıl $[\bar{X}=4.27]$ hizmet süresine sahip öğretmenlerin algılarından daha yüksektir. Bunun yanında öğretmenlerin algıları örgütsel erdemlik ölçeğinin toplamı $\left[F_{(295)}=2.562 ; p>.05\right]$, güven ve nezaket $\left[F_{(295)}=.945 ; p>.05\right]$, iyimserlik $\left[F_{(295)}=2.179 ; p>.05\right]$, içsel doyum $\left[F_{(295)}=2.263\right.$; $p>.05]$, dişsal doyum $\left[F_{(295)}=2.143 ; p>.05\right]$ boyutları ve iş doyumu ölçeğinin toplamı $\left[F_{(295)}=1.901 ; \quad p>.05\right]$ için hizmet yılına göre istatiksel anlamda farklılık göstermemektedir.

Öğretmenlerin örgütsel erdemlilik ve iş doyumu algılarının okul kademesine göre farklılık gösterip göstermediğini belirlemek amacıyla t-Testi yapılmış ve ulaşılan sonuçlar Tablo 5'te verilmiştir. 
Tablo 5

Öğretmenlerin Örgütsel Erdemlilik ve İş Doyumu Algllarına İlişkin Okul Kademesi Değişkeni Açısından t-Testi Sonuçları

\begin{tabular}{|c|c|c|c|c|c|c|c|c|c|}
\hline & $\begin{array}{l}\text { Okul } \\
\text { Kademesi }\end{array}$ & $n$ & $\bar{X}$ & SS & $\mathrm{F}$ & $p$ & $t$ & SD & $p$ \\
\hline \multirow{2}{*}{$\begin{array}{l}\text { Dürüstlük ve } \\
\text { Bağışlayıcılık }\end{array}$} & İlkokul & 83 & 4.55 & 0.88 & \multirow{2}{*}{2.668} & \multirow{2}{*}{.103} & \multirow{2}{*}{1.468} & \multirow{2}{*}{296} & \multirow{2}{*}{.143} \\
\hline & Ortaokul & 215 & 4.36 & 1.04 & & & & & \\
\hline \multirow{2}{*}{ Güven ve Nezaket } & İlkokul & 83 & 4.66 & 0.96 & \multirow{2}{*}{1.369} & \multirow{2}{*}{.243} & \multirow{2}{*}{.821} & \multirow{2}{*}{296} & \multirow{2}{*}{.413} \\
\hline & Ortaokul & 215 & 4.55 & 1.05 & & & & & \\
\hline \multirow{2}{*}{ İyimserlik } & İlkokul & 83 & 4.45 & 1.00 & \multirow{2}{*}{.198} & \multirow{2}{*}{.657} & \multirow{2}{*}{.605} & \multirow{2}{*}{296} & \multirow{2}{*}{.545} \\
\hline & Ortaokul & 215 & 4.37 & 1.04 & & & & & \\
\hline \multirow{2}{*}{ Örgütsel Erdemlilik } & İlkokul & 83 & 4.56 & 0.84 & \multirow{2}{*}{1.558} & \multirow{2}{*}{.213} & \multirow{2}{*}{1.041} & \multirow{2}{*}{296} & \multirow{2}{*}{.299} \\
\hline & Ortaokul & 215 & 4.43 & 0.98 & & & & & \\
\hline \multirow{2}{*}{ İçsel Doyum } & İlkokul & 83 & 3.77 & 0.69 & \multirow{2}{*}{.851} & \multirow{2}{*}{.357} & \multirow{2}{*}{1.810} & \multirow{2}{*}{296} & \multirow{2}{*}{.071} \\
\hline & Ortaokul & 215 & 3.63 & 0.60 & & & & & \\
\hline \multirow{2}{*}{ Dişsal Doyum } & İlkokul & 83 & 3.48 & 0.72 & \multirow{2}{*}{.889} & \multirow{2}{*}{.346} & \multirow{2}{*}{1.840} & \multirow{2}{*}{296} & \multirow{2}{*}{.067} \\
\hline & Ortaokul & 215 & 3.32 & 0.65 & & & & & \\
\hline \multirow{2}{*}{ İş Doyumu } & İlkokul & 83 & 3.63 & 0.66 & 1856 & 174 & 1060 & 206 & 050 \\
\hline & Ortaokul & 215 & 3.47 & 0.58 & & & & & \\
\hline
\end{tabular}

Tablo 5'e bakıldığında öğretmenlerin algıları dürüstlük ve bağışlayıcılık $\left[t_{(296)}=1.468 ; p>.05\right]$, güven ve nezaket $\left[t_{(296)}=.821 ; p>.05\right]$, iyimserlik $\left[t_{(296)}=.605\right.$; $p>.05]$, içsel doyum $\left[t_{(296)}=1.810 ; p>.05\right]$, dişsal doyum $\left[t_{(296)}=1.840 ; p>.05\right]$ boyutları, örgütsel erdemlilik $\left[t_{(296)}=1.041 ; p>.05\right]$ ve iş doyum ölçeğinin toplamı $\left[t_{(296)}=1.969\right.$; $p>.05]$ için okul kademesi değişkeni açısından istatiksel anlamda farklılık göstermemektedir. Bu bulguya göre ilkokul ve ortaokulda görev yapan öğretmenlerin örgütsel erdemlilik ve iş doyumu algıları benzer şekilde gerçekleşmiştir.

İlkokul ve ortaokullarda görev yapmakta olan öğretmenlerin algılarına göre öğretmenlerin örgütsel erdemlilik ile iş doyum düzeyleri arasındaki ilişkiyi belirlemek için yapılan Pearson moment çarpımı korelasyon analizi sonuçları Tablo 6'da verilmiştir.

Tablo 6'ya bakıldığında örgütsel erdemlilik ile iş doyumu arasında pozitif yönde orta düzeyde anlamlı bir ilişki olduğu görülmektedir $[r=.449, p<.01]$. Bunun yanında örgütsel erdemliliğin alt boyutları ile iş doyumu arasındaki ilişki incelendiğinde; dürüstlük ve bağışlayıcılık $[r=.480, p<.01]$, güven ve nezaket $[r=.416, p<.01]$ ve iyimserlik $[r=.350, p<.01]$ boyutları ile iş doyumu arasında pozitif yönde orta düzeyde anlamlı bir ilişki bulunmaktadır. 
Tablo 6

Örgütsel Erdemlilik ile İs Doyumu Arasındaki İlişki

\begin{tabular}{|c|c|c|c|c|c|c|c|}
\hline & $\begin{array}{l}\text { Dürüstlük ve } \\
\text { Bağışlayıcılık }\end{array}$ & $\begin{array}{l}\text { Güven ve } \\
\text { Nezaket }\end{array}$ & İyimserlik & $\begin{array}{c}\text { Örgütsel } \\
\text { Erdemlilik }\end{array}$ & $\begin{array}{c}\text { İçsel } \\
\text { Doyum }\end{array}$ & $\begin{array}{l}\text { Dişsal } \\
\text { Doyum }\end{array}$ & $\begin{array}{c}\text { İş } \\
\text { Doyumu }\end{array}$ \\
\hline $\begin{array}{l}\text { Dürüstlük ve } \\
\text { Bağışlayıcılık }\end{array}$ & 1 & & & & & & \\
\hline Güven ve Nezaket & $.838^{* *}$ & 1 & & & & & \\
\hline İyimserlik & $.743^{* *}$ & $.752^{* *}$ & 1 & & & & \\
\hline Örgütsel Erdemlilik & $.931^{* * *}$ & $.936^{* *}$ & $.902^{* *}$ & 1 & & & \\
\hline İçsel Doyum & $.359^{* *}$ & $.350^{* *}$ & $.304^{* *}$ & $.366^{* *}$ & 1 & & \\
\hline Dişsal Doyum & $.527^{* *}$ & $.420^{* *}$ & $.344^{* *}$ & $.465^{* *}$ & $.723^{* *}$ & 1 & \\
\hline İş Doyumu & $.480^{* *}$ & $.416^{* *}$ & $.350^{* *}$ & $.449^{* *}$ & $.923^{* *}$ & $.933^{* *}$ & 1 \\
\hline
\end{tabular}

Öğretmenlerin örgütsel erdemlilik algılarının iş doyumlarını yordamasına ilişkin yapılan çoklu doğrusal regresyon analizi sonuçları Tablo 7'de yer almaktadır.

Tablo 7

İş Doyumunun Yordanmasına İlişkin Çoklu Doğrusal Regresyon Analizi Sonuçları

\begin{tabular}{lccccccc}
\hline Değişken & $\mathrm{B}$ & Standart Hata & $\beta$ & $t$ & $p$ & İkili $r$ & Kismi $r$ \\
\hline Sabit & 2.228 & .150 & & 14.817 & .000 & & \\
Dürüstlük ve Bağışlayıcılık & .275 & .060 & .455 & 4.606 & .000 & 0.480 & 0.259 \\
Güven ve Nezaket & .035 & .059 & .060 & .601 & .549 & 0.416 & 0.035 \\
İyimserlik & -.020 & .048 & -.034 & -.414 & .680 & 0.350 & -0.024 \\
\hline $\mathrm{R}=.481$ & $\mathrm{R}^{2}=.231$ & & & & & & \\
$\mathrm{~F}_{(3.294)}=29.520$ & $\mathrm{p}=.000$ & & & & & & \\
\hline
\end{tabular}

Tablo 7'ye bakıldığında dürüstlük ve bağışlayıcılık, güven ve nezaket ve iyimserlik değişkenleri birlikte öğretmenlerin iş doyum puanları ile orta düzeyde anlamlı bir ilişki içerisinde olduğu görülmektedir $\left[R=.481, R^{2}=.231, F_{(3.294)}=29.520\right.$, $p=.000]$. Bunun yanında bu değişkenler birlikte iş doyumundaki toplam varyansın $\%$ 23 'ünü açıklamaktadır. Bu sonuca göre öğretmenlerin iş doyumu düzeylerinde meydana gelen değişimin \%23'ünün öğretmenlerin örgütsel erdemlilik algılarından kaynaklandığı söylenebilir. Öte yandan regresyon katsayısına $(\beta)$ göre yordayıcı değişkenlerin iş doyumu üzerindeki önem sırası dürüstlük ve bağışlayıcılık, güven ve nezaket ve iyimserlik şeklindedir.

\section{Tartışma, Sonuç ve Öneriler}

$\mathrm{Bu}$ çalışma, öğretmenlerin örgütsel erdemlilik algıları ve iş doyumu düzeyleri arasındaki ilişkiyi belirlemek ve bu algıların öğretmenlerin bazı demografik özelliklerine (cinsiyet, yaş, hizmet y1lı ve okul kademesi) göre farklılaşıp 
farklılaşmadığını tespit etmek amacıyla yapılmıştır. Araştırma çerçevesinde öncelikle öğretmenlerin erdemlilik algılarında ve iş doyumu düzeylerinde demografik değişkenler açısından farklılık olup olmadığı belirlenmiş ardından öğretmenlerin erdemlilik algıları ile iş doyumu düzeyleri arasındaki ilişki saptanmıştır. Ayrıca öğretmenlerin örgütsel erdemlilik algılarının iş doyumu düzeylerini yordamasına bakılmıştır.

Araştırmanın sonuçlarına göre ilkokul ve ortaokullarda görevli öğretmenlerin erdemlilik algılarının yüksek düzeyde $(\bar{X}=4.47)$ olduğu görülmektedir. Elde edilen bulgular yapılan bazı çalışmaların (Baş \& Şentürk, 2011; Buluç, 2008; Cameron, 2011) bulgularıyla benzerlik göstermektedir. Öğretmenlerin erdemlilik alg1 boyutları incelendiğinde örgütsel erdemlilik algısının en yüksek "güven ve nezaket" ( $\bar{X}=4.58)$, en düşük "iyimserlik" ( $\bar{X}=4.40)$ boyutlarında olduğu görülmüştür. Bu bulgulara bakılarak güven ve nezaket ile iyimserlik boyutlarında öğretmenlerin görev yaptıkları kurumda saygı ve nezaket kurallarına uygun davrandıkları, diğer çalışanlara güvendikleri, kendilerini kurumlarına adadıkları ve başarıya inandıkları sonucuna varılmıştır. Söz konusu sonuca benzer olarak Baş ve Şentürk (2011) araştırmasında öğretmenlerin kendilerini örgütlerine adama davranışına sahip olduklarını ve örgüt içindeki saygı, güven ortamına önem verdiklerini tespit etmiştir.

Örgütsel erdemlilik ölçeğinden elde edilen puanlara bakıldığında öğretmenlerin erdemlilik algıları cinsiyet değişkeni açısından dürüstlük ve bağışlayıcılık boyutunda ve örgütsel erdemliliğin boyutlarının toplam puanlarında anlamlı farklılık göstermiştir. Benzer olarak Aktaş (2008) çalışmasının sonucunda bağışlayıcı ve uyumlu davranışlar sergileme noktasında cinsiyet değişkeni açısından erkeler lehine anlamlı farklılık bulmuştur. Farklı olarak ise Yılmaz ve Taşdan (2009) araştırmasında öğretmenlerin iyimser, bağışlayıcı davranışlarında cinsiyet değişkeni açısından anlamlı bir farklılık bulamamıştır. Söz konusu bulgulardan hareketle kadınların ve erkeklerin sergilediği bağışlayıcılık, iyimserlik ve dürüstlük davranışlarının değişkenlik gösterdiği söylenebilir.

Öğretmenlerin erdemlilik algılarına yaş değişkeni açısından bakıldığında ölçekten elde edilen puanlar, dürüstlük ve bağışlayıcılık boyutunda anlamlı farklılık gösterirken güven ve nezaket ile iyimserlik boyutlarında anlamlı farklılık göstermemiştir. Elde edilen bulgulara göre 41 ve üzeri yaş grubunda buluna öğretmenlerin algıları 21-30 ve 31-40 yaş gruplarında bulunan öğretmenlerden daha yüksektir. Yancı (2011) araştırmasında, kurumdaki bağışlayıcı davranışlar ve dürüstlüğe olan inancın ileri yaşlar için anlamlı farklılık gösterdiğini tespit etmiştir. Söz konusu araştırma sonuçları bakımından bu çalışmanın bulgularıyla paralel niteliktedir. Ulaşılan sonuçlara bakılarak öğretmenlerin yaşları ilerledikçe hatalara karşı bağışlayıcı, hoşgörülü ve anlayışlı oldukları, hatalardan ders çıkarmaya dikkat ettikleri, çalıştıkları kurumda saygı unsurunu ön planda tuttukları ve kurumun itibarına, erdemlilik algısına önem verdikleri söylenebilir.

Örgütsel erdemlilik ölçeğinden elde edilen puanlara göre öğretmenlerin erdemlilik algısı, okul kademesi değişkeni bakımından anlamlı farklılık göstermemiştir. Bu bağlamda yapılan çalışmalarda (Kepenek, 2008; Yaylacı, 2004; Yılmaz \& Taşdan, 2009) bazı yönleriyle bu bulgulara benzer bazı yönleriyle ise söz konusu bulgulardan farklı sonuçlar elde edilmiştir. Yılmaz ve Taşdan (2009), çalışmasında öğretmenlerin erdemlilik algısında okul kademesi değişkeninde ilköğretim okulları lehine anlamlı farklılık tespit etmiştir. Yaylacı (2004) ve Kepenek (2008) araştırmalarında 
öğretmenlerin erdemlilik algılarında okul türü değişkenine göre anlamlı farklılık olduğunu belirlemiştir ve söz konusu farklılı̆̆ı ilköğretim okullarında çalışan öğretmenlerin daha bağışlayıcı, saygıdan yana, iyimser olduğu şeklinde ifade etmiştir. $\mathrm{Bu}$ bulgulara bakılarak öğretmenlerin çalışma ortamındaki saygı, dürüstlük, bağışlayıcılık, iyimserlik, hataları hoş görme ve kurum lehine çevirebilme davranışlarının branşlara göre benzer olduğu ama okul türüne göre ilköğretim okullarında söz konusu davranışların daha yaygın olduğu söylenebilir.

Öğretmenlerin erdemlilik algılarına hizmet yılı değişkeni yönüyle bakıldığında ölçekten elde edilen puanlar için güven ve nezaket ile iyimserlik boyutlarında anlamlı farklılıktan söz edilemezken dürüstlük ve bağışlayıcılık boyutunda anlamlı farklılık mevcuttur. Bulgular incelendiğinde 11-20 y1l ve 21 yıl üzeri hizmet y1lına sahip olan öğretmenlerin erdemlilik algılarının 1-10 yıl hizmet süresine sahip olan öğretmenlerin algılarından daha yüksek olduğu görülmüştür. Benzer olarak Yancı (2011) araştırmasında çalışma yılı arttıkça öğretmenlerin anlayışlı olma, güven duyma, affedebilme ve adil olma davranışlarının da arttığını belirlemiştir. $\mathrm{Bu}$ sonuçlara bakılarak hizmet yılı değişkeninin öğretmenlerin çalıştıkları ortamda dürüst ve bağışlayıcı olabilme özelliklerine verdikleri önemle pozitif yönde ilişkili olduğu söylenebilir.

Araştırma sonuçlarına göre ilkokul ve ortaokullarda görev yapan öğretmenlerin iş doyumu puanlarının yüksek ( $\bar{X}=3.52)$ olduğu görülmüştür. Elde edilen bulgular Kumaş ve Deniz (2010) ile Karataş ve Güleş (2010) tarafından yapılan çalışmalar ile paralellik göstermektedir. Şahin (2013) çalışmasında öğretmenlerin iş doyumlarını "kısmen doyumlu" bulmuştur. Günbayı ve Toprak (2010) ile Erdem ve Demirel (2009) ise öğretmenlerin iş doyumlarının orta düzeyde olduğu sonucuna ulaşmışlardır. İş doyumunun alt boyutlarındaki ortalamalarda içsel doyumun $(\bar{X}=3.67)$ ortalamasının dişsal doyumdan ( $\bar{X}=3.37$ ) yüksek olduğu görülmüştür.

İş doyumu ölçeğinden elde edilen puanlara göre öğretmenlerin iş doyumu algıları cinsiyet değikenine göre istatistiksel olarak anlamlı bir farklılık göstermemektedir. Çalışmanın sonuçları bazı çalışmalarla benzerlik gösterirken (Avşaroğlu, Deniz, \& Kahraman, 2005; Erdem \& Demirel, 2009; K1ş, Gür, \& Akçamete, 2012; Kumaş \& Deniz, 2010; Şahin, 2013; Taşdan \& Tiryaki, 2008; Uslu, 1999); bazı çalışmalarla farklılık göstermektedir. Abd-ElFattah (2010), Akiri ve Ugborugbo (2009) ve Michaelowa (2002) kadınların iş doyumu algılarını erkeklerden daha yüksek bulmuş; Bishay (1996) ise erkeklerin iş doyumu algılarının kadınlardan daha yüksek olduğunu belirtmiştir. İş doyumunun cinsiyete göre değişken sonuçlar vermesinin yaşanılan bölge, kültür, kadının toplumdaki yeri vb. etkenlere bağlı olduğu düşünülebilir (Şahin, 2013).

Öğretmenlerin iş doyumu algıları yaş değişkeni açısından incelendiğinde yaş grupları arasında istatistiksel olarak anlamlı bir farklılık olmadığı görülmüştür. Benzer çalışmalar yapan Erdem ve Demirel (2009), Şahin (2013) ve Şahin ve Dursun (2009) da yaşa göre anlamlı bir fark elde etmemişlerdir. Bunun yanında Günbayı ve Toprak (2010) yaş değişkenine göre gruplar arasında manidar farklar bulmuşlardır. Çalışma sonuçlarına göre 31-40 yaş grubundaki öğretmenlerin iş doyumu düzeyleri 51 ve üzeri yaş grubundaki öğretmenlerden daha düşük bulunmuştur. Kumaş ve Deniz (2010) de öğretmenlerin iş doyumlarında yaş değişkenine göre manidar farklar bulmuşlardır. 
Sonuçlara göre 20-25 yaş aralığındaki öğretmenlerin içsel ve dışsal iş doyumları diğer öğretmenlere kıyasla daha yüksektir. Öğretmenlerin iş doyumu algıları hizmet yılı değikenine göre incelenmiş ve istatistiksel olarak anlamlı bir fark elde edilmemiştir. Sonuçlar Kış ve diğerleri (2012), Taşdan ve Tiryaki, Erdem ve Demirel (2009), Şahin ve Dursun'un (2009) çalışmaları ile benzerlik göstermektedir. Ancak Akiri ve Ugborugbo (2009) araştırmaları sonucunda hizmet yılındaki artışın iş doyumunu azalttı̆̆ı kanısına varmışlardır.

Öğretmenlerin iş doyumu ölçeğinden elde edilen puanlara göre okul kademesi değişkeni incelenmiştir ve iş doyumu puanları ile okul kademesi arasında istatistiksel olarak anlamlı bir fark bulunmamıştır. Kış ve diğerleri (2012) kendi çalışmalarında benzer sonuçlar elde etmişlerdir. Kumaş ve Deniz (2010) ise öğretmenlerin iş doyumu algılarının okul türü değişkenine göre manidar biçimde farklılaştığını tespit etmişlerdir. Araştırma sonuçlarına göre ilköğretim birinci ve ikinci kademe öğretmenlerinin içsel ve dışsal iş doyumları genel lise, Anadolu ve meslek liselerinde görev yapan öğretmenlere göre daha yüksektir. Ayrıca meslek lisesinde görev yapan öğretmenlerin içsel iş doyumlarının genel liselerde ve Anadolu liselerinde görev yapan öğretmenlere göre daha yüksek olduğu sonucuna ulaşılmıştır.

Öğretmenlerin örgütsel erdemlilik algıları ile iş doyumu düzeyleri arasında pozitif yönde orta düzeyde anlamlı bir ilişki olduğu görülmüştür. Ayrıca öğretmenlerin örgütsel erdemlilik algılarının öğretmenlerin iş doyumu düzeylerini anlamlı bir şekilde yordadığ1 sonucuna ulaşılmıştır. Bu bulgudan hareketle örgütsel erdemlilik algısı yüksek olan öğretmenlerin erdemlilik algısı düşük olan öğretmenlere göre işleriyle daha barışık, iş ortamında mutlu ve yaptıkları işin kendilerini tatmin etme düzeyinin daha yüksek olduğu söylenebilir. Öte yandan örgütsel erdemliliğin Erdemliliğin alt boyutları ile iş doyumu arasındaki ilişki incelendiğinde erdemliliğin tüm alt boyutları (güven ve nezaket, iyimserlik, dürüstlük ve bağışlayıcılık) ile iş doyumu arasında pozitif yönde ve orta düzeyde anlamlı bir ilişki olduğu görülmektedir. Bu bulgular öğretmenlerin çalıştıkları ortamda güven duyma, nezaket gösterme, saygılı olma, dürüst davranma ve bağışlayıcı olabilme algılarını geliştirdiklerinde yaptıkları işe karşı daha olumlu bakış açısıyla yaklaşabileceklerini, yaptıkları işin kendilerini mutlu edeceğini, çalışma ortamlarında huzur bulabileceklerini, kendilerini daha yetkin, özgür ve değerli hissedeceklerini göstermektedir. Dolayısıyla iş doyumu düzeyi yüksek olan öğretmen işine, görev yaptığı kuruma daha bağlı ve özverili bir çalışma şekline sahip olacağından bu durumun hem çalışma ortamının iklimini hem de kurumun performansını olumlu yönde etkileyeceği söylenebilir.

Araştırmadan elde edilen sounuçlara göre öğretmenlerin örgütsel erdemlilik algıları arttıkça iş doyumu düzeyleri de yükselmektedir. Okulların başarısı ve öğretmenlerin motivasyonlarının bu anlamda yüksek olması açısında örgütsel erdemliliğin önemli olduğu söylenebilir. Bu bağlamda okullarda başta okul yöneticileri olmak üzere tüm çalışanların erdemli davranışlar sergilemesine yönelik etkinlikler düzenlenebilir. Okul yöneticileri bu anlamda rol model olabilir. Bunun yanında okul yöneticileri doğru ödüllendirme sistemleri ile öğretmenlerin kuruma daha çok bağlanmalarını ve kendilerini değerli hissetmelerini sağlayabilirler. Çalışma ortamının huzurunu arttıracak, birlik ve bütünlük oluşturacak etkinlikler düzenlenebilir. Öğretmenler arası işbirliğini arttıracak çalışmalar yürütülebilir. İlgili literatürde örgütsel erdemlilik ile iş doyumu arasındaki ilişkiyi açıklayacak daha fazla çalışmaya ihtiyaç 
vardır. $\mathrm{Bu}$ anlamda hem nicel hem de nitel çalışmalar yapılabilir. Araştırmada öğretmenlerin örgütsel erdemlilik algılarının cinsiyet ve okul kademesi; iş doyumu düzeylerinin ise cinsiyet, yaş, hizmet yılı ve okul kademesi değişkenleri açısından farklılık göstermediği sonucuna ulaşılmıştır. Yukarıda bahsi geçen bu kavramların farklı değişkenler ile ilişkisini inceleyen arştırmalar gerçekleştirilebilir. Örgütsel erdemliliğin okullları bir takım yönlerden etkileyeceği açıktır. Bu nedenle örgütsel erdemlilik ile ilişkili olabilecek adalet, güven, okul kültürü gibi kavramlar ile ilgili araştırmalar yapılabilir. Araştırma Trabzon ilinde devlet okullarında görev yapmakta olan ilkokul ve ortaokul öğretmenleri ile sınırlıdır. Bu nedenle çalışmanın liselere ve üniversitelere yayılmasının, gözlem ve görüşme tekniklerinin kullanılmasının ilgili alanyazına katkı sağlayacağı düşünülmektedir. 


\section{Summary}

Purpose and Significance: The research studies conducted in order to ensure the efficient working and success of the organizations have increased recently. The concept "Organization" is not composed of mechanical systems, contrary to this, organizations exist by their social dimensions rather than physiological structures (Cameron, 2011). Organization culture occurs when social dimensions imaged by organization compounds (Aktan, 1999). Organization culture consists of honesty, sharing, nobleness, goodness of communication and the situation when all these components come together expresses the virtue dimension. Organization virtue expresses the organizations possession levels of systemic favor, moral level, development of social and physiologically, tolerance, honesty, respect and patience (Cameron, 2011). Job satisfaction is the degree of satisfaction of an employee. (Schultz \& Schultz, 1998). In those organizations which have higher virtue levels, people's careers consist of positive situations and person achieves the job satisfaction. Having higher virtue levels and achieving job satisfaction are significantly important for organization's performance and success. It is predicted that this research will create a theoretical background because of the deficiency of the study to determine the relationship between organizational virtue and job satisfaction in both national and international field. The aim of the research is to determine the relationship between the perceptions of organizational virtue and job satisfaction, and to determine whether it differs in terms of demographic variables. On behalf of this main aim, these purposes below are tried to be achieved:

1. How are perceptions of organizational virtuousness and job satisfaction according to the views of teachers?

2. Does the teachers' perceptions of organizational virtuousness and job satisfaction differ significantly in terms of gender, age, years of service and school level?

3 . Is there a meaningful relationship between teachers' perceptions of organizational virtuousness and job satisfaction?

4. Are the organizational virtuousness of the teachers significantly predicting job satisfaction levels?

Method: Correlation type relational scanning method is used in this research by which it is aimed at determining the relationship between organizational virtue perceptions and job satisfaction levels of teachers' who are serving in primary and secondary schools. The study group of the research involved 298 teachers [176 women (\%59.1) and 122 men (\%40.9)] who are working in secondary education in Trabzon province. The scale form which is used for reaching the data for the research consists of 3 parts: In first part "Personal and Professional information form" which is used for determining the demographic information of the participants such as age, gender, marital status, branch, service year and school type, in second part "Scale of Organizational Virtuousness" and in the third part "Job Satisfaction Scale" take place. According to the results of analysis, Cronbach's Alpha value of "Organizational Virtue Scale" is .96, and "Job Satisfaction Scale" is .92. Some statistical analyses are done for analyzing the data by using SPSS package program. Descriptive statistics are done by using average, frequency standard deviation and percentage values depending on teachers' personal and professional 
forms. Average and standard deviation are used for interpreting the teachers' perceptions of organizational virtue and job satisfaction. T-Test, One Way Analysis of Variance (ANOVA), one of the parametric tests, is used for determining whether teachers' organizational virtue perceptions and job satisfaction differ in terms of age, gender, branch, marital status, educational levels, school type and service year variables.

Results: Within the research, firstly, it is examined whether teachers' perceptions of virtue and job satisfaction levels differ in terms of demographic variables or not, then the relationship between teachers' perceptions of virtue and job satisfaction levels are determined. According to the findings of the research;

- Teachers working in primary and secondary schools have a high level of virtuousness perceptions ( $\bar{X}=4.47$ ),

- When sub-dimensions of the virtuousness is taken into consideration, the highest organizational virtuousness perception of teachers is "Confidence and Kindness" ( $\bar{X}=4.58)$, the lowest is "Optimism" ( $\bar{X}=4.40)$,

- While the virtuousness perception of teachers differs in terms of gender, service year and age variables, it does not differ in terms of branch and school type,

- Job satisfaction level of teachers is high ( $\bar{X}=3.52)$,

- In sub-dimensions of job satisfaction, the average of intrinsic satisfaction is ( $\bar{X}$ $=3.67)$ higher than extrinsic satisfaction $(\bar{X}=3.37)$ and the points of job satisfaction does not significantly differ in terms of demographic variables,

- There is a medium level significant relationship in positive way between organizational virtuousness and job satisfaction $(r=.449, p<.01)$,

- When sub-dimensions of virtuousness and job satisfaction are examined, there is a medium level significant relationship in positive way between job satisfaction and the dimensions; honesty and forgiveness $(r=.480, p<.01)$, confidence and kindness $(r=.416, p<.01)$, and optimism $(r=.350, p<.01)$.

Discussion and Conclusion: There is a medium level significant relationship in positive way between teachers' virtuousness perceptions and job satisfaction levels. This finding shows that teachers' perceptions of virtuousness affect job satisfaction level. In other words, virtuousness perception is a significant regression of job satisfaction. It can be said that the teachers who have higher virtue perception are more reconciled, happier in their workplace and have a higher satisfaction level in terms of job they do than the teachers who have lower virtue perception. There is also a medium level significant relationship in positive way between the all dimensions of virtuousness (confidence and kindness, optimism, honesty and forgiveness) and job satisfaction. These findings show that when teachers improve their perceptions such as trusting, being kind, respecting, behaving honestly and being forgiving inside their workplaces; they may approach their work in more positive perspective, the work they are doing may make them happy, they may find peace in their workplaces and feel themselves more competent, free and valuable. Consequently, since the teacher with high level of job satisfaction will have a more dedicated and devoted working style and this will affect the work environment and the performance of the organization in a positive way. 


\section{Kaynakça}

Abd-El-Fattah, S. M. (2010). Longitudinal effects of pay increase on teachers' job satisfaction: A motivational perspective. The Journal of International Social Research, 3(10), 11-21.

Akbolat, M., Durmuş, A., \& Özgün, Ü. (2017). Örgütsel erdemliliğin personel güçlendirmeye etkisi ve otantik liderliğin araci rolü. Işsletme Bilimi Dergisi, 5(2), 71-88.

Akiri, A.A., \& Ugborugbo, N.M. (2009). Analytic examination of teachers' career satisfaction in public secondary schools. Studies on Home and Community Sciences, 3(1), 51-56.

Aktan, C. C. (1999). Toplam ahlak felsefesi ve toplam ahlak yönetimi. Toplam Ahlâk, 11-23.

Aktaş, H. G. (2008). Öğretmenlerde denetim odağl ve örgütsel vatandaşlık (Yayımlanmamış yüksek lisans tezi). Afyon Kocatepe Üniversitesi, Afyonkarahisar.

Arjoon, S. (2000). Virtue theory as a dynamic theory of business. Journal of Business Ethics, 28(2), 159-178.

Avşaroğlu, S., Deniz, M. E., \& Kahraman, A. (2005). Teknik öğretmenlerde yaşam doyumu iş doyumu ve mesleki tükenmişlik düzeylerinin incelenmesi. S. Ü. Eğitim Fakültesi Dergisi, 14, 115-129.

Aydın, A. S., Akyüz, K. C., Yıldırım, İ., \& Şükür, K. (2017). İlk ve ortaokullarda görev yapan öğretmenlerin iş tatmini ve örgütsel bağlılık düzeylerinin analizi. Uluslararası İktisadi ve İdari İncelemeler Dergisi, 1(18), 23-52.

Balnaves, M., \& Caputi, P. (2001). Introduction to quantitative research methods: An investigative approach. Sage Publications.

Baş, G., \& Şentürk, C. (2011). İlköğretim okulu öğretmenlerinin örgütsel adalet, örgütsel vatandaşlık ve örgütsel güven algıları. Kuram ve Uygulamada Eğitim Yönetimi, 17(1), 29-62.

Baycan, F. A. (1985). Farklı gruplarda çalışan kişilerde iş doyumunun bazı yönlerinin analizi (Yayımlanmamış yüksek lisans tezi). Boğaziçi Üniversitesi, İstanbul.

Bishay, A. (1996). Teacher motivation and career satisfaction: A study employing the experienced sampling method. Psychology Journal of Undergraduate Science, 3, 147-154.

Bright, D. S., Cameron, K. S., \& Caza, A. (2006). The amplifying and buffering effects of virtuousness in downsized organizations. Journal of Business Ethics, 64(3), 249269.

Budiman, A., Anantadjaya, S., \& Prasetyawati, D. (2014). Does job satisfaction influence organizational citizenship behavior? An empirical study in selected 4-star hotels in Jakarta, Indonesia. Review of Integrated Business and Economics Research, 3(1), 130-149.

Buluç, B. (2008). Ortaöğretim okullarında örgütsel sağlık ile örgütsel vatandaşlık davranışları arasındaki ilişki. Türk Ë̆itim Bilimleri Dergisi, 6(4), 571-602. 
Büyüköztürk, Ş. (2009). Sosyal bilimler için veri analizi el kitabı (10. Baskl). Ankara: Pegem Akademi.

Cameron, K. (2011). Responsible leadership as virtuous leadership. Journal of Business Ethics, 98(1), 25-35.

Cameron, K. S., Bright, D., \& Caza, A. (2004). Exploring the relationships between organizational virtuousness and performance. American Behavioral Scientist, 47(6), 766-790.

Collins, J. C. (2001). Good to great: Why some companies make the leap... and others don't. Random House.

Comte-Sponville, A. (2004). El capitalismo, es moral. Grupo Planeta (GBS).

Demirdağ, S. (2015). Otantik liderlik ve örgütsel vatandaşlık davranışlarının karşılaştırılması öğretmen adayları. Journal of Turkish Studies, 10(15), 273-273.

Demirtaş, H. (2010). Dershane öğretmenlerinde örgütsel bağl1lık ve iş doyumu. Inönü Üniversitesi Ë̆itim Fakültesi Dergisi, 11(2), 177-206.

Demirtaş, Z. (2015). The relationship between job satisfaction and organizational commitment: a study on elementary schools. Kastamonu Education Journal, 23(1), 253-268.

Diri, M.S., \& Kıral, E. (2016). Ortaokul öğretmenlerinin iş doyumlarinin mesleki tükenmişlik düzeylerine etkisi. Mehmet Akif Ersoy Üniversitesi Ĕ̆itim Fakültesi Dergisi, 39, 125-149.

Erdem, A.R., \& Demirel, F. (2009). Sınıf öğretmenlerinin “denetim” boyutuna ilişkin iş doyum düzeyi. E-Journal of New World Sciences Academy 4(1), 101-119.

Erkmen, T., \& Esen, E. (2012). Örgütsel erdemlilik ölçeginin uyarlanmasi: geçerlik ve güvenirlik çalışması. Business and Economics Research Journal, 3(4), 107-121.

Erkuş, A. (2011). Davranış bilimleri için bilimsel araştırma süreci (2. Baskı). Ankara: Seçkin Yayıncılık.

Fernando, M., \& Almeida, S. (2012). The organizational virtuousness of strategic corporate social responsibility: A case study of the Sri Lankan family-owned enterprise MAS Holdings. European Management Journal, 30(6), 564-576.

Getahun, T., Tefera, B. F., \& Burichew, A. H. (2016). Teacher's job satisfaction and 1ts relationship with organizational commitment in ethiopian primary schools: focus on primary schools of bonga town. European Scientific Journal, ESJ, 12(13), 380-401.

Günbayı, İ., \& Toprak, D. (2010). İlköğretim okulu sınıf ve özel sınıf öğretmenlerinin iş doyum düzeylerinin karşılaştırılması. Illköğretim Online, 9(1), 150-169.

Judge, T. A., Heller, D., \& Mount, M. K. (2002). Five-factor model of personality and job satisfaction: A meta-analysis. Journal of applied psychology, 87(3), 530.

Karababa, A., \& Acun-Kapıkıran, N. (2014). Psikolojik danışmanlarda olumlu-olumsuz mükemmelliyetçilik düzeylerinin iş ve yaşam doyumunu yordamadaki rolü. Türk Psikolojik Danışma ve Rehberlik Dergisi, 5(42), 138-147.

Karasar, N. (2005). Bilimsel araştırma yöntemi (14. Baskı). Ankara: Nobel Yayın Dağıtım.

Karataş, S., \& Güleş, H. (2010). İlköğretim okulu öğretmenlerinin iş tatmini ile örgütsel bağlılığı arasındaki ilişki. Uşak Üniversitesi Sosyal Bilimler Dergisi 3(2), 74-89. 
Kaynak, S. (2007). Öğretmenlerin kişilik özellikleri ve örgütsel vatandaşlık davranışı (Yayımlanmamış yüksek lisans tezi). Afyon Kocatepe Üniversitesi, Afyonkarahisar.

Kepenek, Ö. (2008). Öğretmenlerin meslek etik ilkelerinin örgütsel vatandaşlık davranışına etkisi (Kocaeli İli Örneği) (Yayımlanmamış yüksek lisans tezi). Sakarya Üniversitesi, SBE, Sakarya.

Kış, A. Gür, H., \& Akçamete, G. (2012). Engelli öğretmenlerin iş doyumları ve çalışma koşulları. Mehmet Akif Ersoy Üniversitesi Eğitim Fakültesi Dergisi, 23, 272-294.

Kooshki, S. A., \& Zeinabadi, H. (2016). The role of organizational virtuousness in organizational citizenship behavior of teachers: The test of direct and indirect effect through job satisfaction mediating. International Review, (1-2), 7-21.

Kooshki, S. A., \& Zeinabadi, H. (2015). An investigation into the role of organizational virtuousness in the job attitudes of teachers. Jurnal UMP Social Sciences and Technology Management, 3(1), 563-570.

Koruklu, N., Feyzioğlu, B., Özenoğlu-Kiremit, H., \& Aladağ, E. (2013). Öğretmenlerin iş doyumu düzeylerinin bazı değişkenlere göre incelenmesi. Mehmet Akif Ersoy Üniversitesi Eğitim Fakültesi Dergisi, 13(25), 119-137.

Kumaş, V., \& Deniz, L. (2010). Öğretmenlerin iş doyum düzeylerinin incelenmesi. M.Ü. Atatürk Ĕ̈itim Fakültesi Eğitim Bilimleri Dergisi, 32,123-139.

Mehboob, F., \& Bhutto, N. A. (2012). Job satisfaction as a predictor of organizational citizenship behavior a study of faculty members at business institutes. Interdisciplinary journal of contemporary research in business, 3(9), 1447-1455.

Michaelowa, K. (2002). Teacher career satisfaction, student achievement, and the cost of primary education in Francophone SubSaharan Africa. Hamburg: Institute of International Economics.

Nartgun, S. S., \& Dilekci, U. (2016). Teacher views on administrators' leadership styles and level of organizational virtuousness. The Anthropologist, 24(1), 363-372.

Ocak, H. (2011). Bir ahlak felsefesi problemi olarak erdem kavramina yüklenen anlamin ilkçağdan ortaçağa evrimi. Felsefe ve Sosyal Bilimler Dergisi (FLSF), 11, 79-101.

Özkalp, E., \& Kocacık, F. (1991). Davranış bilimlerine giriş. Eskişehir Anadolu Üniversitesi, A.Ö.F. Yayınları, No: 75.

Özkan, A. (2017). Illkokul ve ortaokul öğretmenlerinin iş doyumu düzeyleri (Balıkesir ili merkez ilçeler örneği) (Yayımlanmamış yüksek lisans tezi). Balıkesir Üniversitesi, Sosyal Bilimler Enstitüsü, Balıkesir.

Peterson, C. (2003). Classification of positive traits in youth. Promoting Positive Child, Adolescent, and Family Development, 4, 227-255.

Rego, A., Ribeiro, N., \& Cunha, M. P. (2010). Perceptions of organizational virtuousness and happiness as predictors of organizational citizenship behaviors. Journal of Business Ethics, 93(2), 215-235.

Ribeiro, N., \& Rego, A. (2009). Does perceived organizational virtuousness explain organizational citizenship behaviors. International Journal of Social and Human Sciences, 3, 736-743. 
Roodt, G., Rieger, H., \& Sempane, M. E. (2002). Job satisfaction in relation to organisational culture. SA Journal of industrial Psychology, 28(2), 23-30.

Şahin, H., \& Dursun, A. (2009). Okul öncesi öğretmenlerinin iş doyumları: Burdur örneği. Mehmet Akif Ersoy Üniversitesi Ĕ̈itim Fakültesi Dergisi, 18, 160-174.

Şahin, İ. (2013). Öğretmenlerin iş doyumu düzeyleri, YYÜ Eğitim Fakültesi Dergisi, 10(1), 143-168.

Schermerhorn, J. R., Hunt, J. G., Osborn, R. N., \& Uhl-Blen, M. (2010). Organizational behavior. USA: Wiley Inc.

Schultz, D. P., \& Schultz, S. E. (1986). Psychology and industry today: An introduction to industrial and organizational psychology (4th ed.). New York, NY, England: Macmillan Publishing Co, Inc.

Sezgin, F., \& Kılınç, A. Ç. (2012). İlköğretim okulu öğretmenlerinin mesleki tükenmişlik düzeyleri ile örgütsel vatandaşlık davranışları arasındaki ilişki. Ahi Evran Üniversitesi Kırşehir Ë̆itim Fakültesi Dergisi, 13(3), 103-127.

Taşdan, M., \& Tiryaki, E. (2008). Özel ve devlet ilköğretim okulu öğretmenlerinin iş doyumu düzeylerinin karşıllaştırılması. Eğitim ve Bilim, 33(147), 54-70.

Uslu, M. (1999). Resmi eğitim kurumlarında çalışan psikolojik danışma ve rehberlik uzmanlarının iş doyumu ve tükenmişlik düzeylerinin danışmanların denetim odă̆ ve bazı değişkenlere göre karşılaştırılması (Yayımlanmamış yüksek lisans tezi). Selçuk Üniversitesi, Sosyal Bilimler Enstitüsü, Konya.

Vallett, C. M. (2010). Exploring the relationship between organizational virtuousness and culture in continuing higher education. The Journal of Continuing Higher Education, 58(3), 130-142.

Weiss, D. J., Dawis, R. V. England, G. W., \& Lofquist, L. H. (1967). Manual for the minnesota satisfaction questionnaire. c: 22, Minnesota studies in vocational rehabilitation. Minneapolis: University of Minnesota, Industrial Relations Center.

Werang, B. R., \& Agung, A. A. G. (2017) Teachers' job satisfaction, organizational commitment, and performance in Indonesia: A Study from Merauke District, Papua. International Journal of Development and Sustainability, 6(8), 700-711.

Wu, V., \& Short, P. M. (1996). The relationship of empowerment to teacher job commitment and job satisfaction. Journal of Instructional Psychology, 23(1), 8589.

Yanc1, F. (2011). Ortaöğretim okulu öğretmenlerinin duygusal zeka düzeyleri ile örgütsel vatandaşlık davranışları arasındaki ilişki (Şanlıurfa ili örneği) (Yayımlanmamış yüksek lisans tezi). Harran Üniversitesi, Şanlıurfa.

Yaylac1, A. F. (2004). Illköğretim okullarl yönetici ve öğretmenlerinin örgütsel yurttaşlık davranışları (Yayımlanmamış doktora tezi). Ankara Üniversitesi, Eğitim Bilimleri Enstitüsü, Ankara.

Y1lmaz, K., \& Taşdan, M. (2009). Organizational citizenship and organizational justice in Turkish primary schools. Journal of Educational Administration. 47(1), 108-126. 